\section{7} 8

8

\title{
Bioinformatic exploration of RIO protein kinases of parasitic and free-living nematodes
}

\author{
Q1 Bert Breugelmans a , Aaron R. Jex a, Pasi K. Korhonen ${ }^{a}$, Stefano Mangiola ${ }^{a}$, Neil D. Young a , \\ Paul W. Sternberg ${ }^{b}$, Peter R. Boag ${ }^{c}$, Andreas Hofmann ${ }^{a, d}$, Robin B. Gasser ${ }^{a, *}$ \\ ${ }^{a}$ Faculty of Veterinary Science, The University of Melbourne, Parkville, Victoria, Australia \\ ${ }^{\mathrm{b}}$ Howard Hughes Medical Institute (HHMI), Division of Biology, California Institute of Technology, Pasadena, CA, USA \\ ${ }^{\mathrm{c}}$ Faculty of Medicine, Nursing and Health Sciences, Monash University, Clayton, Victoria, Australia \\ ${ }^{\mathrm{d}}$ Structural Chemistry Program, Eskitis Institute, Griffith University, Brisbane, Australia
}

\section{A R T I C L E I N F O}

\section{Article history:}

Received 1 May 2014

Received in revised form 17 June 2014

Accepted 18 June 2014

Available online $\mathrm{xxxx}$

\section{Keywords:}

Parasitic nematode

RIO kinase

Structure

Function

\begin{abstract}
A B S T R A C T
Despite right open reading frame kinases being essential for life, their functions, substrates and cellular pathways remain enigmatic. In the present study, gene structures were characterised for 26 right open reading frame kinase from draft genomes of parasitic and free-living nematodes. RNA-seq transcription profiles of right open reading frame kinase genes were investigated for selected parasitic nematodes and showed that these kinases are transcribed in developmental stages that infect their mammalian host. Three-dimensional structural models of Caenorhabditis elegans right open reading frame kinases were predicted, and elucidated functional domains and conserved regions in nematode homologs. These findings provide prospects for functional studies of RIO kinase genes in C. elegans and an opportunity for the design and validation of nematode-specific inhibitors of these enzymes in socioeconomic parasitic worms.
\end{abstract}

(c) 2014 Published by Elsevier Ltd. on behalf of Australian Society for Parasitology Inc.

\section{Introduction}

Parasitic diseases continue to be a substantial burden on human and animal health worldwide. This burden is compounded by food and water shortages as well as poor sanitation (Hotez et al., 2009). The World Health Organization (WHO) estimates that more than 1 billion people are currently affected by parasitic nematodes and that the impact of these worms surpasses diabetes or lung cancer in disability adjusted life years (DALYs) (http://www.who.int/en/). Considering the limited number of approved anthelmintic drugs for widespread use in humans or other animals, current treatment programs to control these nematodes can lead to drug resistance (Osei-Atweneboana et al., 2011), requiring continued efforts to search for new interventions. The traditional approach of highthroughput screening for drug discovery is costly and has yielded only a small number of anthelmintic drugs, with no novel classes approved for use in humans in decades (Keiser and Utzinger, 2010). An alternative approach is to understand the molecular and biochemical pathways in parasitic nematodes to guide future discovery efforts.

\footnotetext{
* Corresponding author. Tel.: +61 3 97312000; fax: +61 397312366. E-mail address: robinbg@unimelb.edu.au (R.B. Gasser).
}

Major advances in high-throughput sequencing have led to a substantial expansion in the availability of genomic and transcriptomic data for parasitic nematodes in recent years. To date, the draft genomes of Trichinella spiralis (clade I) (Blaxter et al., 1998); Ascaris suum, Brugia malayi, Loa loa (clade III); Strongyloides ratti, Bursaphelenchus xylophilus, Meloidogyne hapla, Panagrellus redivivus (clade IV); Haemonchus contortus and Pristionchus pacificus (clade V) have been published (Ghedin et al., 2007; Abad et al., 2008; Dieterich et al., 2008; Opperman et al., 2008; Jex et al., 2011; Kikuchi et al., 2011; Mitreva et al., 2011; Desjardins et al., 2013; Laing et al., 2013; Schwarz et al., 2013; Srinivasan et al., 2013). In addition to the extensive genomic research linked to species of Caenorhabditis (e.g., Caenorhabditis elegans Sequencing Consortium, 1998; Gupta and Sternberg, 2003), these draft genomes represent a massive resource for the scientific community working on fundamental and applied aspects of parasitic worms.

The benefits of these resources can now be realised through a collective effort of mining and curating smaller datasets such as particular gene families involved in essential biological processes. Protein kinases (PKs) are one of the largest gene families of metazoans and regulate a wide range of cellular processes including cell-cycle progression, transcription, DNA replication and meta- 
bolic processes (Vanrobays et al., 2001; LaRonde-LeBlanc et al., 2005; LaRonde-LeBlanc and Wlodawer, 2005a; Granneman et al., 2010; Campbell et al., 2011; Widmann et al., 2012; Read et al., 2013). PKs can activate/inactivate target proteins by catalysing the transfer of phosphate groups to specific residues (i.e. His/Asp, Ser/Thr/Tyr and Arg) on their target proteins and thus play a regulatory role in nearly all cell signalling pathways (Hanks et al., 1988). Presently, PKs can be divided into eukaryotic protein (ePKs), protein kinase-like (PKL) and atypical protein (aPK) kinases. For instance, of more than 500 human PKs, less than 10\% are PKL proteins, many of which were previously classified as aPKs. The PKL kinases represent 19 families, one being the right open readingframe kinases (RIOKs) (Kannan et al., 2007; Manning et al., 2011).

In the present study, we extend previous studies of RIOKs of selected strongylid nematodes (Hu et al., 2008; Campbell et al., 2011; Ansell et al., 2013), indicating that they (i) are likely to be crucial for development, survival and/or reproduction, (ii) are conserved among nematodes, but (iii) are divergent from related molecules in other ecdysozoans and vertebrates. Multicellular organisms studied to date all have three riok genes (riok-1, riok-2 and riok-3). Functional studies of these genes in Saccharomyces cerevisiae (yeast), Caenorhabditis elegans (elegant worm), Drosophila melanogaster (vinegar fly) and vertebrate cell lines indicate key roles of RIOKs in ribosome maturation, cell-cycle progression and/or chromosome stability (Vanrobays et al., 2001; Angermayr and Bandlow, 2002; Geerlings et al., 2003; Ceron et al., 2007; Simpson et al., 2008; Granneman et al., 2010; Strunk et al., 2011; Widmann et al., 2012; Esser and Siebers, 2013). Recently, another study (Read et al., 2013) has indicated that D. melanogaster riok-2 (Dmeriok-2) is involved in cell cycle progression through the regulation of the Akt signalling pathway, suggesting that riok-2 might be part of a complex cell-cycle signalling system. In spite of this information, the essential roles of RIOKs have only been assumed for most organisms, including parasitic nematodes (Vanrobays et al., 2001; LaRonde-LeBlanc et al., 2005; LaRonde-LeBlanc and Wlodawer, 2005a; Granneman et al., 2010; Campbell et al., 2011; Widmann et al., 2012; Read et al., 2013). To date, structural information for the RIOK family is based on two crystal structures for Afu-RIOK-1 and Afu-RIOK-2 of Archaeoglobus fuldigus (Archaea) and on CthRIOK-2 of Chaetomium thermophilum (thermophilic fungus) (LaRonde-LeBlanc and Wlodawer, 2004; LaRonde-LeBlanc et al., 2005; Ferreira-Cerca et al., 2012). Remarkably, the latter, fungal kinase acts in vitro as an ATPase rather than a kinase, suggesting that RIOKs might be involved in a process that is distinct from the assumed canonical serine/threonine kinase activity (Ferreira-Cerca et al., 2012). Gaining insights into the structural characteristics and molecular functions of RIOKs, and their involvement in cellular pathways, might provide a basis for the future design of novel drugs against parasitic nematodes. As a first step, we undertook here a detailed investigation of the riok gene family in 12 nematode species representing different phylogenetic clades, and for which draft genomes and transcriptomes are presently available.

\section{Materials and methods}

\subsection{Gene prediction and identification}

We extracted genomic, transcriptomic and protein datasets for the identification, isolation and curation of full-length riok genes from 13 nematode species from WormBase (WS238 www.worm base.org) for C. elegans, Caenorhabditis briggsae, T. spiralis, L. loa, A. suum, B. xylophilus, M. hapla, Meoidogyne incognita and from other repositories for $H$. contortus (GenBank Assembly IDs: GCA_000469685.1 and GCA_000442195.1), P. redivivus (GenBank Assembly ID: GCA_000341325.1), P. pacificus (http://www.pristion chus.org), S. ratti (GenBank Assembly ID: GCA_000208845.1) and B. malayi (GenBank Assembly ID: AAQA00000000.1). Using partial, inferred amino acid (aa) sequences of RIOK proteins, riok genes were located and extracted using the programs BLAT (Kent, 2002) and Exonerate (Slater and Birney, 2005). Transcription was established by identifying the corresponding riok transcripts in the transcriptomes of individual nematode species, and each gene was manually curated to verify that it was full-length. Using a web-based application (http://wormweb.org/exonintron), gene structures and functional protein domains were displayed. The nomenclature of RIOKs followed the guidelines of WormBase (www.wormbase.org). Genes/proteins were named according to an abbreviation of the binomial species name, followed by the gene and the gene number. For example, riok-1 of C. elegans is called Cel-riok-1, and the encoded protein is Cel-RIOK-1.

\subsection{Phylogenetic analysis of nematode RIOKs}

Phylogenetic analysis of sequence data was conducted using Bayesian inference, employing the program MrBayes 3.1.2 (http:// mrbayes.csit.fsu.edu/index.php). Posterior probabilities (pp) were calculated for RIOK aa sequences, using 2,000,000 generations, a burnin fraction of 0.25 , employing four simultaneous tree-building chains, saving every 100th tree. For each of the three RIOK subfamilies, a phylogenetic tree was constructed based on aa sequence alignments of the minimum kinase domain. RIOK sequences from T. spiralis were used as outgroups. Correlations between evolutionary distance (sum of branch lengths between the different RIOKs through the Python library, BioPhylo [http://biopython.org/DIST/ docs/api/Bio.Phylo-module.html]) and gene-structural characteristics such as intron length, coding length, gene length, number of exons, as well as species genome size, were calculated using R (linear regression function) for members of each RIOK subfamily.

\subsection{Transcription profiling of nematode RIOKs}

Transcription profiles of riok genes were characterised in different developmental stages of the parasitic nematodes $H$. contortus, $A$. suum and $B$. malayi using extensive RNA-seq data with biological replicates $(n \geqslant 3)$ for $H$. contortus and B. malayi (Jex et al., 2011; Laing et al., 2013; Schwarz et al., 2013). RNA-seq data for A. suum (SRP010159 and SRP026668) and H. contortus (SRP026668) were extracted from the Sequence Read Archive (SRA) (http:// www.ncbi.nlm.nih.gov/sra). Brugia malayi RNA-seq data were available from the Wellcome Trust Sanger Institute, UK, and were obtained from http://www.ebi.ac.uk/ena/data/view/PRJEB2709. The full-length rioks were re-predicted for each species genomic sequence. Trimmomatic software was used, as described in Schwarz et al. (2013), to filter the paired-end RNA-seq reads for quality in individual samples (representing different developmental stages and tissues). Each set of the 'decontaminated' and quality filtered paired-end RNA-seq data was mapped to each species genomic sequence, using Burrows-Wheeler Aligner (BWA) software (Li and Durbin, 2010). The reads that mapped to each riok were extracted using the program SAMtools (Li et al., 2009). For each developmental stage, the $\log _{10}$ value of the resultant read counts was used as input data to produce heat-maps. The same scaling was used for expression levels in parasitic nematodes and $D$. melanogaster; low expression $\left(\log _{10}\right.$ value $\left.0-2\right)$, moderate expression ( $\log _{10}$ value $\left.2-4\right)$ and high expression ( $\log _{10}$ value $\left.>4\right)$ were defined. Read counts were used as input data for edgeR (Robinson et al., 2010). Initially, levels of differential transcription were calculated by pairwise comparisons among different developmental stages or sexes of each nematode. Using edgeR-calculated common and gene-wise dispersion factors, genes from $H$. contortus and $B$. malayi with multiple RNA-seq biological replicates $(n=3)$ were considered 
210 differentially transcribed if the fold-change compared with the nor211 malised read count data was $\geqslant 4$, and the false discovery rate was $212 \leqslant 0.05$. For $A$. suum, transcript abundance was assumed to follow a 213 Poisson distribution in edgeR. In this case, genes were considered 214 differentially transcribed if the normalised fold-change between 215 the read counts of pairwise samples was $\geqslant 4$, and the $P$-value was $216 \leqslant 10^{-05}$.

\subsection{Structural analysis of nematode RIOKs}

Structure-based aa sequence alignments were generated with SBAL (Wang et al., 2012), and conserved and novel domains identified. Three-dimensional (3D) models were built for full length and truncated Cel-RIOK-1, -2 and -3 and for their N- and C-terminal domains. The ab initio modeling was based on multiple-threading sequence alignments and iterative template fragment assembly simulations using I-TASSER, by matching individually generated, 3D models with the BioLiP protein function database, which also contains the known crystal structures of A. fuldigus (i.e. Afu-RIOK-1 and -2) and C. thermophilum (Cth-RIOK-2) (Roy et al., 2010, 2012; Zhang, 2008). Models with a positive C-score (i.e. confidence score for estimating the quality of the predicted model, ranging between -5 and 2 ) and the highest TM-score (TeMplate quality-score of the generated 3D model and a known RIOK crystal structure) were selected, and functional predictions, including gene ontology (GO) terms, enzyme classification and putative ligand binding sites, were determined individually for the RIOK proteins and for their $\mathrm{N}$ - and $\mathrm{C}$ terminal domains. Finally, consensus sequences of kinase activityrelated domains for the Cel-RIOKs and RIOKs of eight other nematode species were created using MUSCLE-guided alignments (Edgar, 2004), and nematode-specific consensus sequences were generated and displayed using WebLogo software (Crooks et al., 2004).

\section{Results}

\subsection{Detailed characterisation of riok genes in nematodes}

Based on the three characterised Cel-rioks (WBGene00019698, WBGene00013688 and WBGene00014012), we identified partial rioks in the draft genomes of 12 other nematode species for which After manual curation, full-length gene sequences were defined for each riok-1 to -3 for eight of the 12 nematodes (Table 1 ). No full-length rioks were found for the three plant-parasitic nematodes, B. xylophilus, M. hapla and M. incognita, or the free-living nematode $P$. redivivus (clade IV). An incomplete sequence of riok1 was identified for $P$. pacificus (Ppa-riok-1); however, this sequence did encode a putatively functional kinase domain and was therefore retained for subsequent analyses. On average, nematode rioks display a gene length of 4,300 bp, nine exons, an open reading frame (ORF) of $\sim 1,500 \mathrm{bp}$, and are translated into RIOK proteins with a mean length of 510 aa (Table 1 ).

Twenty-six full-length riok gene structures were defined for Table S1). The regions recognised to be essential for kinase activity (Angermayr and Bandlow, 2002; LaRonde-LeBlanc and Wlodawer, 2004; LaRonde-LeBlanc et al., 2005; Esser and Siebers, 2013) were derived from multiple sequence alignments, and are displayed together with the gene structures (Fig. 1). The number of exons varies from 1 to 17 , depending on the species and riok subfamily, with a mean of 10 , nine and eight exons for riok-1, -2 and -3 , respectively (Table 1; Fig. 1). The gene structures of each of the three rioks are relatively conserved between species within clade III and have the same number of exons. In addition, individual riok extensive published genomic/transcriptomic data are available. nine nematode species representing clades I-V (Supplementary structures of B. malayi and $L$. loa are the same. There is also a degree of conservation in gene structure for the rioks of $C$. elegans and C. briggsae (clade V). Compared with the small numbers of exons (varying from three to eight) in the three rioks of these Caenorhabditis spp., other members of this clade, including the cosmopolitan nematode $P$. pacificus and the parasitic nematode $H$. contortus, have rioks with more than 10 exons. We did not find a relationship between genome size of the nematodes, lengths of individual rioks or numbers of exons in these genes. For instance, the clade I nematode, $T$. spiralis, has the most complex riok gene (Tsp-riok-1; 17 exons), which is slightly longer than the average of $4,300 \mathrm{bp}$ for all nematode rioks studied here. Strongyloides ratti has the smallest genome $(52 \mathrm{Mb})$, the shortest riok gene lengths and the smallest numbers of exons. In contrast, $A$. suum and $H$. contortus have the largest genome sizes (273 and $320 \mathrm{Mb}$, respectively) and have the longest riok-1 and riok-2 genes that have only 11-12 exons. The riok-3 gene of $H$. contortus (3,382 bp) is, however, shorter than those of $B$. malayi and $L$. loa (5,148 and 5,026 bp, respectively), with genome sizes of 91-94 Mb and possessing 11 exons.

We defined the locations of three protein-encoding regions in the gene structures that are linked to kinase activity, and an additional N-terminal domain, most likely adopting a fold of a wingedhelix domain (Fig. 1). This domain is encoded in the riok-2 genes of all nematode species studied and spans the first $3^{\prime}$-end exons. The ATP binding region (P-loop) encoded in riok-2 is located on the same or the following exon, and the catalytic and metal binding regions are located towards the $3^{\prime}$-end of the gene on two neighbouring exons. For riok-3, the 5'-end (3-6 exons) codes for a domain of unknown function (DUF), whereas the ATP binding region spans the two following exons present in clade III and $\mathrm{V}$ nematodes. For riok-1, the 5'-end (1-8 exons) codes for a DUF, followed by the ATP-binding region. The catalytic region of riok-1 of $S$. ratti (clade $\mathrm{V}$ ) and $T$. spiralis (clade I) spans two exons, followed by the metal-binding region on the same exon.

\subsection{Transcription profiles of riok genes in different life stages of parasitic nematodes}

Transcripts of riok-1, riok-2 and riok-3 were detected in all developmental stages of the three parasitic nematodes studied here, namely $H$. contortus, $B$. malayi and $A$. suum. The transcription profiles of $H$. contortus rioks were very similar for two independent RNA-seq datasets (Laing et al., 2013; Schwarz et al., 2013). In both datasets, the transcription level of Hco-riok-3 was slightly higher compared with Hco-riok-1 and Hco-riok-2, and the transcription levels of Hco-riok-1 and -2 were similar and consistent throughout the parasite's development (Fig. 2). No major differences in transcription for any of the rioks were detected between the adult females and males of $H$. contortus. Also, in B. malayi (Ghedin et al., 2007), transcription levels for the rioks were relatively consistent throughout development, with highest levels in adult females (Fig. 2). In A. suum, the transcription of all three genes was highest in the egg stage and, for Asu-riok-3, it was relatively consistent throughout development. We observed a slight elevation in transcription of Asu-riok-2 in L4s, but did not detect any difference in transcription for any of the rioks between the two sexes of A. suum (Fig. 2). An analysis of available RNA-seq data did not reveal any alternatively spliced transcripts for the three rioks of A. suum, B. malayi or $H$. contortus. This finding is inconsistent with the two splice variants (Cel-riok-1a and -1b) of the riok-1 in C. elegans. The ORFs of both Cel-riok-1 splice variants were the same across the first six exons. A stop codon at the seventh exon of splice variant Cel-riok-1b results in a truncated version of the RIOK protein (Fig. 3). This truncated protein does not contain catalytic and metal-binding regions required for kinase activity 
Table 1

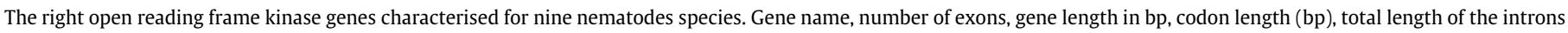
(bp) and the full-length right open reading-frame kinase protein (amino acids, aa) are presented for each riok gene and species.

\begin{tabular}{|c|c|c|c|c|c|c|c|}
\hline Species & Genome size (Mb) & Gene name & Exons & Gene length (bp) & Coding length (bp) & Intron length (bp) & Protein length (aa) \\
\hline \multirow[t]{3}{*}{ Strongyloides ratti } & \multirow[t]{3}{*}{52} & Sra-riok-1 & 3 & 1,709 & 1,530 & 179 & 510 \\
\hline & & Sra-riok-2 & 2 & 1,621 & 1,569 & 52 & 523 \\
\hline & & Sra-riok-3 & 1 & 1,696 & 1,695 & 0 & 565 \\
\hline \multirow[t]{3}{*}{ Ascaris suum } & \multirow[t]{3}{*}{309} & Asu-riok-1 & 11 & 7,425 & 1,533 & 5,892 & 511 \\
\hline & & Asu-riok-2 & 12 & 12,489 & 1,587 & 10,902 & 529 \\
\hline & & Asu-riok-3 & 11 & 7,465 & 1,530 & 5,935 & 510 \\
\hline \multirow[t]{3}{*}{ Brugia malayi } & \multirow[t]{3}{*}{94} & Bma-riok-1 & 11 & 4,281 & 1,479 & 2,802 & 493 \\
\hline & & Bma-riok-2 & 12 & 3,425 & 1,470 & 1,955 & 490 \\
\hline & & Bma-riok-3 & 11 & 5,026 & 1,488 & 3,538 & 496 \\
\hline \multirow[t]{3}{*}{ Loa loa } & \multirow[t]{3}{*}{91} & Llo-riok-1 & 11 & 4,783 & 1,485 & 3,298 & 495 \\
\hline & & Llo-riok-2 & 12 & 3,521 & 1,545 & 1,976 & 515 \\
\hline & & Llo-riok-3 & 11 & 5,148 & 1,518 & 3,630 & 506 \\
\hline \multirow[t]{3}{*}{ Caenorhabditis briggsae } & \multirow[t]{3}{*}{104} & Cbr-riok-1 & 6 & 1,806 & 1,545 & 261 & 515 \\
\hline & & Cbr-riok-2 & 5 & 3,064 & 1,596 & 1468 & 532 \\
\hline & & Cbr-riok-3 & 6 & 1,712 & 1,461 & 251 & 487 \\
\hline \multirow[t]{3}{*}{ Caenorhabditis elegans } & \multirow[t]{3}{*}{100} & Cel-riok-1 & 8 & 4,922 & 1,518 & 3,404 & 506 \\
\hline & & Cel-riok-2 & 3 & 4,953 & 1,587 & 3,366 & 529 \\
\hline & & Cel-riok-3 & 5 & 2,516 & 1,530 & 986 & 510 \\
\hline \multirow[t]{3}{*}{ Pristionchus pacificus } & \multirow[t]{3}{*}{64} & Ppa-riok-1 & Incomplete & 3,842 & 570 & 3,272 & 190 \\
\hline & & Ppa-riok-2 & 14 & 3,563 & 1,575 & 1,988 & 525 \\
\hline & & Ppa-riok-3 & 10 & 2,334 & 1,656 & 678 & 552 \\
\hline \multirow[t]{3}{*}{ Haemonchus contortus } & \multirow[t]{3}{*}{320} & Hco-riok-1 & 11 & 7,865 & 1,338 & 6,527 & 446 \\
\hline & & Hco-riok-2 & 13 & 6,835 & 1,587 & 5,248 & 529 \\
\hline & & Hco-riok-3 & 14 & 3,382 & 1,512 & 1,870 & 504 \\
\hline \multirow[t]{3}{*}{ Trichinella spiralis } & \multirow[t]{3}{*}{64} & Tsp-riok-1 & 17 & 4,904 & 1,740 & 3,164 & 580 \\
\hline & & Tsp-riok-2 & 9 & 2,954 & 1,302 & 1,652 & 434 \\
\hline & & Tsp-riok-3 & 6 & 2,071 & 1,392 & 679 & 464 \\
\hline
\end{tabular}

(Angermayr and Bandlow, 2002; LaRonde-LeBlanc and Wlodawer, 2004; LaRonde-LeBlanc et al., 2005; Esser and Siebers, 2013).

\subsection{Phylogenetic relationships of RIOK proteins of nematodes}

Phylogenetic analyses of inferred protein sequence data by Bayesian inference displayed the relationships of individual RIOKs representing distinct nematode clades (Blaxter et al., 1998) (Supplementary data S1-S3) (Fig. 4). For individual RIOKs, the proteins of $C$. elegans and C. briggsae (clade V) grouped more closely together than to those of $H$. contortus (clade $\mathrm{V}$ ), and all of them grouped together with absolute support $(\mathrm{pp}=1.00$ ), to the exclusion of RIOKs representing clade III. However, the RIOK-2 and -3 of $P$. pacificus grouped together ( $\mathrm{pp}=0.70-0.84$ ) with homologues of the other species representing clade $V$. The proteins of the filarioids $L$. loa and $B$. malayi (clade III) grouped more closely together than homologues of A. suum (clade III), and all of them grouped together with absolute support $(\mathrm{pp}=1.00)$. These two distinct groups of RIOKs representing clades V and III, respectively, grouped to the exclusion of those representing clades I and IV. Therefore, for each of the three RIOKs, the proteins grouped according to their respective evolutionary nematode clade, with those of $T$. spiralis (clade I) being most evolutionarily distant. There was a positive correlation between the evolutionary distance of the RIOKs and two gene-structural characteristics: the number of exons $(P<0.001)$ and coding length $\left(P<0.1 \mathrm{E}^{-06}\right)$.

\subsection{Structural analysis and functional predictions of nematode RIOKS}

Three-dimensional structural models were predicted ab initio for Cel-RIOK-1, -2 and -3 , to infer the minimum kinase domains and DUFs. The Cel-RIOK models were built based on the crystal structure of Cth-RIOK-2 (fungus) (Fig. 5 and Supplementary Figs. S1-S3). For Cel-RIOK-2, the full-length protein (winged-helix, minimal kinase domain and C-DUF) was modelled, while partial proteins were modelled to $\mathrm{Cel}$-RIOK-1 (i.e. minimal kinase domain and C-DUF) and Cel-RIOK-3 (i.e. minimal kinase domain). The $\mathrm{N}$-lobe, Hinge region and $\mathrm{C}$-lobe that form the minimum kinase domain are predicted to be crucial for kinase activity (LaRonde-LeBlanc and Wlodawer, 2004; LaRonde-LeBlanc et al., 2005), and the number and location of their secondary structure motifs (i.e. $\alpha$-helices and $\beta$-strands) are conserved among the three Cel-RIOKs (Fig. 5). The secondary structures that comprise the $\mathrm{N}$ lobe are: three $\beta$-strands that form the P-loop (the ATP-binding region), an $\alpha$-helix and a fourth $\beta$-strand. The two $\beta$-strands of the Hinge region connect the $\mathrm{N}$-lobe to the $\mathrm{C}$-lobe; the latter lobe contains an $\alpha$-helix, followed by two $\beta$-strands that engulf the catalytic region, which is separated from the metal-binding region (with two $\beta$-strands) by a short 8-10 aa tract, replacing the activation loop present in the sequences of other kinases, which binds to the substrate (Fig. 5).

Contrary to the conserved, minimum kinase domain, the $\mathrm{N}$ - and C-terminal domains differ considerably in length as well as predicted secondary structure elements (Fig. 5). The N-terminal domain of Cel-RIOK-1 is 130 aa in length and is comprised of four $\boldsymbol{\alpha}$-helices (Fig. 5 and Supplementary Table S2), whereas the C-terminal domain (168 aa) contains a short $\beta$-strand and $\alpha$-helix, followed by a bundle of four $\alpha$-helices. This assembly is similar to that of the C-terminal domain of Cel-RIOK-2 (Fig. 5). The N-terminal domain (92 aa) of Cel-RIOK-2 has four $\alpha$-helices and two $\beta$-strands that form a fold, known as the winged-helix structure, plus an additional $\alpha$-helix. In this context, the longest, extending $\mathrm{N}$-terminal domain is found in Cel-RIOK-3 (242 aa) and comprises two $\alpha$-helices and a $\beta$-strand, followed by three $\alpha$-helices. The C-terminal domain of Cel-RIOK-3 is the shortest in this comparison (58 aa) and contains a $\beta$-strand and two $\alpha$-helices. Structural homology models were inferred for the $\mathrm{N}$ - and C-terminal domains of Cel-RIOK-1 and -3 that were not included in the initial Cel-RIOK 


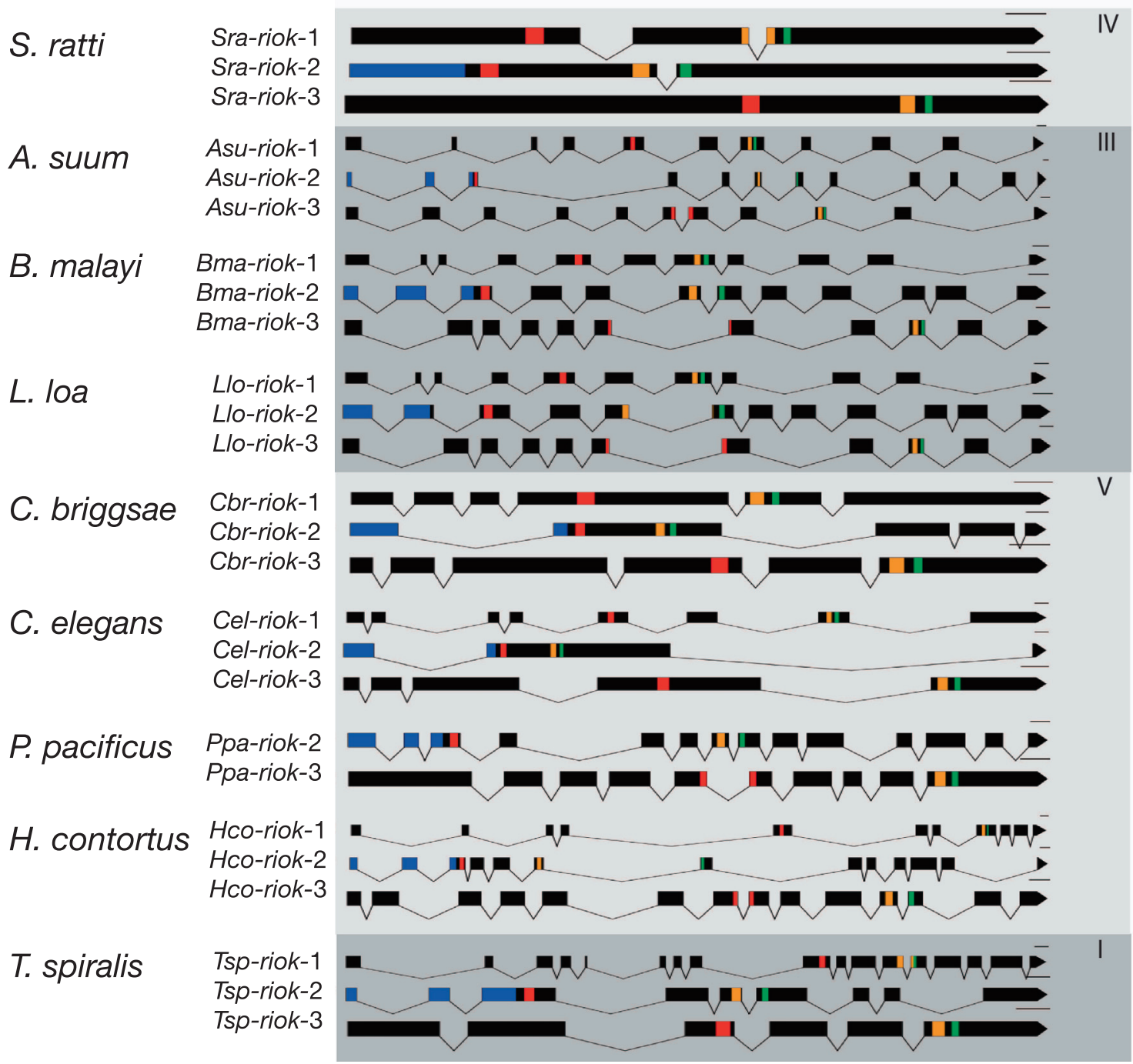

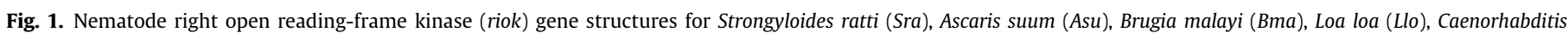
briggsae (Cbr), Caenorhabditis elegans (Cel), Pristionchus pacificus (Ppa), Haemonchus contortus (Hco) and Trichinella spiralis (Tsp). The structures of 26 riok genes are displayed (black blocks represent exons and the connecting lines represent introns, using a $100 \mathrm{bp}$ scale). Different functional regions are indicated within the exon blocks by coloured bars and show their location in the mature protein (blue for the winged helix domain, red for the ATP binding region, orange for the catalytic region and green for the metal binding region).

\begin{tabular}{|c|c|c|c|c|c|c|c|}
\hline & Egg & L1 & L2 & L3 & L4 & Af & Am \\
\hline Hco-riok-1 & 3.15 & 2.68 & 2.44 & 2.81 & 2.62 & 3.07 & 2.91 \\
\hline Hco-riok-2 & 3.06 & 2.76 & 2.25 & 2.35 & 2.18 & 2.90 & 2.46 \\
\hline Hco-riok-3 & 3.63 & 3.55 & 3.43 & 3.78 & 3.97 & 4.11 & 4.12 \\
\hline
\end{tabular}

\begin{tabular}{|c|c|c|c|c|c|c|c|}
\hline & \multicolumn{2}{|c|}{ Egg } & MFil & L3 & L4 & Af & Am \\
\hline Bma-riok-1 & 3.22 & 3.22 & 2.60 & 2.41 & 2.74 & 3.04 & 2.93 \\
\hline Bma-riok-2 & 2.92 & 2.92 & 2.34 & 2.27 & 2.75 & 3.09 & 2.85 \\
\hline Bma-riok-3 & 2.83 & 2.83 & 2.17 & 2.51 & 2.56 & 3.10 & 2.61 \\
\hline
\end{tabular}

$\begin{array}{llllllll} & & \text { Egg } & & \text { L3 } & \text { L4 } & \text { Af } & \text { Am } \\ \text { Asu-riok-1 } & 3.89 & 3.89 & 3.89 & 2.57 & 2.91 & 2.96 & 3.10 \\ \text { Asu-riok-2 } & 4.22 & 4.22 & 4.22 & 2.51 & 3.79 & 3.12 & 3.27 \\ \text { Asu-riok-3 } & 3.33 & 3.33 & 3.33 & 2.53 & 2.59 & 2.54 & 2.56\end{array}$

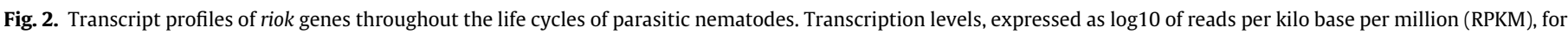

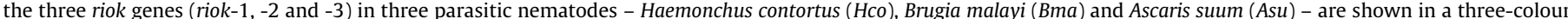

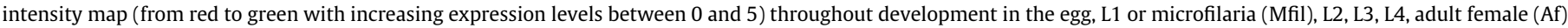
and adult male (Am). Infectious/parasitic stages are indicated in red.

models, and GO terms were assigned to Cel-RIOK-1-N-DUF (i.e. actin binding, protein localisation, muscle contraction), Cel-RIOK-1-C-DUF (kinase regulator activity, transmembrane trans- porter activity, cell death), Cel-RIOK-3-N-DUF (ATPase activity, toxin receptor binding, drug transport) and Cel-RIOK-3-C-DUF (ion binding, integral to membrane) (Supplementary Table S2).

Please cite this article in press as: Breugelmans, B., et al. Bioinformatic exploration of RIO protein kinases of parasitic and free-living nematodes. Int. J. Parasitol. (2014), http://dx.doi.org/10.1016/j.ijpara.2014.06.005 


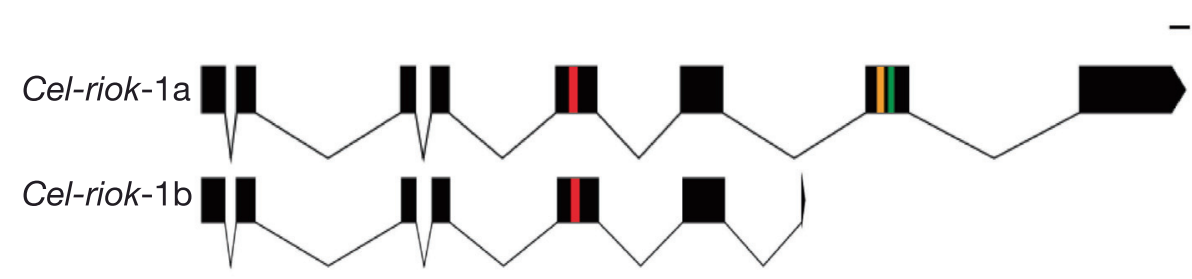

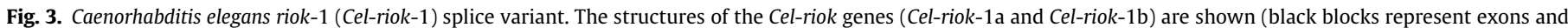

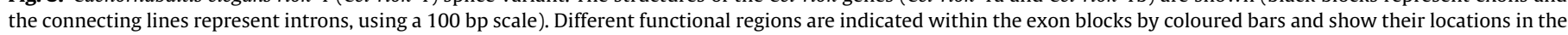
mature protein (red for the ATP binding region, orange for the catalytic region and green for the metal binding region).

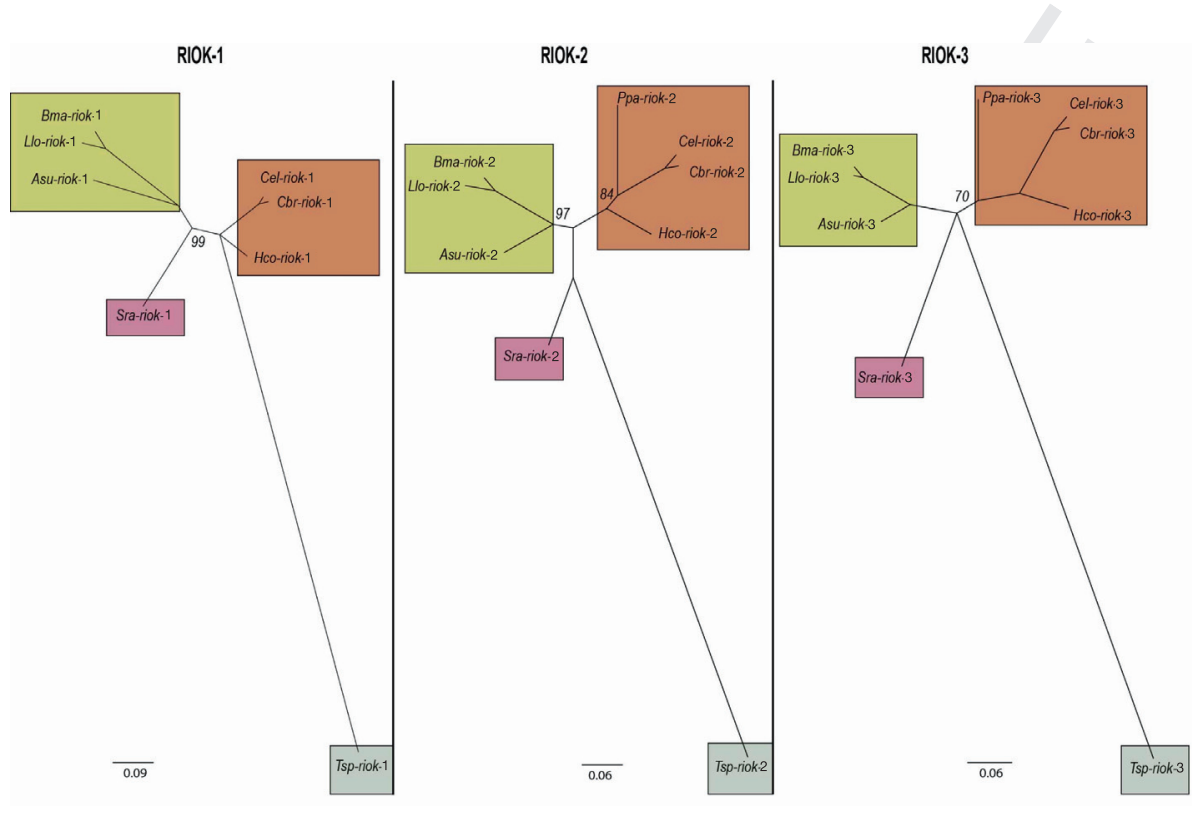

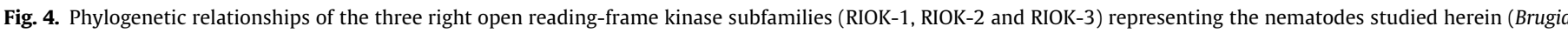

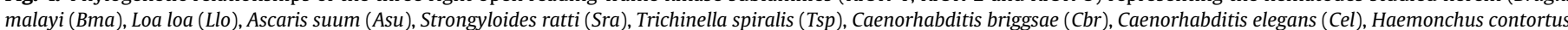

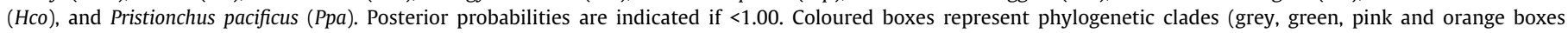
represent phylogenetic clades II-V, respectively).

The consensus sequences of the three functional loops (P-loop, catalytic loop and metal-binding loop) of the three RIOKs for nine nematode species showed a higher degree of sequence conservation (52-73\%) than the Hinge region (20-25\%) (Fig. 5). For the three RIOK consensus sequences of the nine nematodes studied, there was neither variation in the catalytic Asp and Asn residues nor was there variation in the Asp and Gln residues of the metal-binding loop which are crucial for the positioning of the $\mathrm{Mn}^{2+}$ ions (LaRonde-LeBlanc and Wlodawer, 2004) (i.e. catalytic loop: Asp 286 to Asn 290 (Cel-RIOK-1), Asp 227 to Asn 232 (Cel-RIOK-2), Asp 388 to Asn 393 (Cel-RIOK-3); metal-binding loop: Asp 302 to Gln 305 (Cel-RIOK-1), Asp 245 to Gln 248 (Cel-RIOK-2), Asp 406 to $\mathrm{Gln} 409$ (Cel-RIOK-3)). The flexible loop is located between the end of the P-loop and the adjacent $\alpha$-helix, and is characteristic of RIOKs (LaRonde-LeBlanc et al., 2005; Hu et al., 2008). The flexible loop is $\sim 20$ aa long, and the conserved sequence pattern for Cel-RIOKs is: T-S/L-X-X-X-F/I-K-X-R/K-X-X-Y-V/H-X-X-X-F/K-R/S.

\section{Discussion}

We combined a bioinformatics approach with manual curation to provide improved insights into functional and structural aspects of the RIOK family of parasitic and free-living nematodes whose draft genomes are publicly available (Ghedin et al., 2007;
Dieterich et al., 2008; Opperman et al., 2008; Jex et al., 2011; Mitreva et al., 2011; Desjardins et al., 2013; Laing et al., 2013; Schwarz et al., 2013; Srinivasan et al., 2013). Due to a lack of reliable culturing systems to propagate parasites in the laboratory and because current gene silencing approaches are unreliable or impractical, functional analyses of genes in parasitic nematodes of animals are challenging (Geldhof et al., 2006; Maule et al., 2011). However, C. elegans represents a practical system for comparative analyses of close orthologues from parasitic nematodes.

From a functional perspective, current information shows that the Cel-riok-1 encodes two splice variants required for viability, endocytosis, fertility and fat storage (Fraser et al., 2000; Ashrafi et al., 2003; Rual et al., 2004; Sönnichsen et al., 2005; Balklava et al., 2007; Ceron et al., 2007). Although the shorter Cel-riok-1b variant has not yet been characterised on a protein level, it lacks catalytic and metal binding regions, suggesting that it is a pseudo-kinase that has a regulatory role via its N-DUF. Contrary to $C$. elegans, analyses of RNA-seq data for three parasitic nematodes of socio-economic importance, A. suum, B. malayi and $H$. contortus, did not have any truncated riok-1 splice variants. Similar to Cel-riok-1, Cel-riok-2 is required for viability and fertility, whereas Cel-riok-3 encodes a RIOK that is not essential in C. elegans (see Fraser et al., 2000; Ashrafi et al., 2003; Rual et al., 2004; Sönnichsen et al., 2005; Balklava et al., 2007; Ceron et al., 2007). Preliminary experiments have predicted lethal null mutations in 


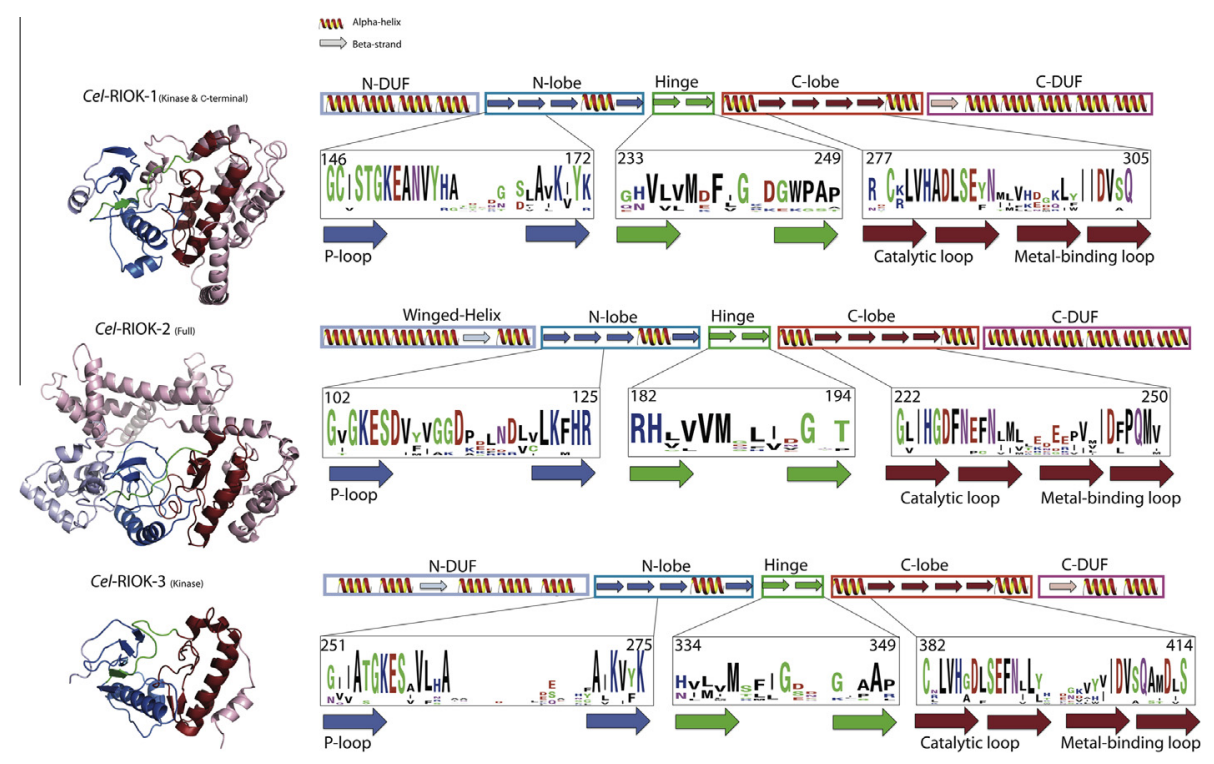

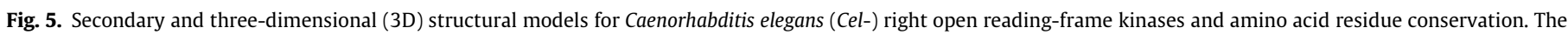

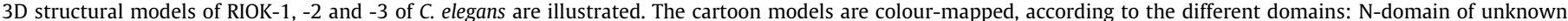

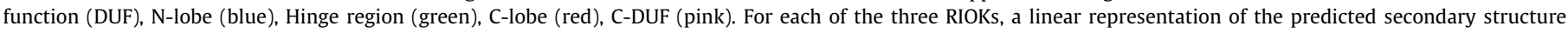

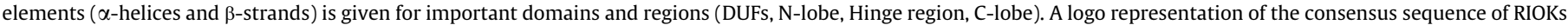

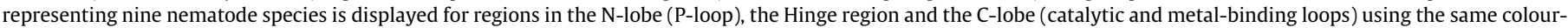
code as the structural cartoon.

Cel-riok-1 and Cel-riok-2 (Boag et al., unpublished data). To date, functional studies of riok genes in non-nematode species have suggested roles in ribosome maturation, cell cycle progression and chromosome stability (Vanrobays et al., 2001; Angermayr and Bandlow, 2002; Geerlings et al., 2003; Ceron et al., 2007: Simpson et al., 2008; Granneman et al., 2010; Strunk et al., 2011; Widmann et al., 2012; Esser and Siebers, 2013). A recent report investigating differential gene expression in glioblastomas of another important metazoan model organism, D. melanogaster, linked over-expression of Dme-riok-2 in these cancer cells to an escape of apoptosis via an up-regulation of the Akt signalling pathway (Read et al., 2013). Interestingly, decreased expression of Dme-riok-1 or Dme-riok-2 resulted in reduced Akt signalling, causing cell cycle exit and apoptosis by inducing p53 activity through the RpL11-dependent ribosomal stress checkpoint (Read et al., 2013). Another study also showed that, in human cell lines, HsaRIOK-1 and -2 interact with proteins that belong to a large complex involved in ribosomal biogenesis, and that $\mathrm{Hsa}$-RIOK-2 is released early from this complex during ribosomal maturation (Widmann et al., 2012). The increased cellular level of released RIOK-2 might be an important regulator of the Akt signalling pathway and might thus serve as a ribosomal stress checkpoint to either progress the cell cycle after the completion of ribosomal maturation or activate the apoptosis pathway upon disruption of ribosomal biosynthesis.

The transcription profiles of rioks are similar among the different developmental stages of three parasitic nematodes of socioeconomic importance: A. suum - the large roundworm that infects pigs or humans, $H$. contortus - a parasite of small ruminants, costing the livestock industry hundreds of millions of dollar per annum, and B. malayi - a major filarial nematode of humans. No detailed developmental transcription profiles have yet been reported for Cel-rioks, but the ModEncode transcription profiles (RNA-seq) of D. melanogaster rioks (www.flybase.org for CG11660, CG11859 and CG3008) display a high degree of similarity to the developmental transcription profiles of the parasitic nematode rioks. Both essential genes (i.e. Dme-riok-1 and Dme-riok-2) are transcribed at moderate levels in embryonic and larval stages (Graveley et al., 2011). This moderate transcription is followed by a decrease in transcription levels during pupation and in adult males, whereas a moderate to high transcription is maintained in adult females. The elevated transcription levels of Dme-riok-1 and Dme-riok-2 in adult females are likely due to the observed elevated levels in the ovaries, while transcription levels in all other tissues are moderate. The transcription levels of Dmeriok-3 are also elevated in the ovaries, salivary glands and digestive system of the adult female. Contrary to Dme-riok-1 and -2 , the transcription of Dme-riok-3 is consistently moderate throughout development, as was observed here for riok-3 transcription in parasitic nematodes. The constant and moderate transcription levels of rioks in the three parasitic nematodes and in D. melanogaster suggest that RIOKs perform house-keeping functions, coinciding with roles in essential pathways, such as ribosome maturation, cell cycle progression and chromosome stability.

Gene compactness, functional essentiality and gene expression/ transcription are known variables of evolutionary rate (Choi and Hannenhalli, 2013). Previous evolutionary studies examined a large number of genes but were restricted to a very small number of complete genomes (S. cerevisiae, C. elegans, D. melanogaster, Mus musculus and Homo sapiens) (Krylov et al., 2003; Liao and Zhang, 2006; Larracuente et al., 2008; Wang and Zhang, 2009). The variability that we observed in gene structures $(n=26)$ representing nine nematode species is remarkable (with exon numbers ranging from one to 17 , and the intron lengths from 52 to $10,000 \mathrm{bp})$ compared with the very similar ORFs and protein lengths for homologous RIOKs $(\sim 1,500 \mathrm{bp}$ relating to $\sim 500$ aa). This variability in gene structure is not related to the genome size or the (parasitic versus free-living) life style of species. We did observe a positive relationship between the riok gene compactness and the respective evolutionary clade of the nematode species, suggesting conservation in riok structure within each phylogenetic clade of nematodes. Functional essentiality of riok genes was neither related to gene structure (gene compactness and intron length) nor to transcription level. Remarkably, none of these observations can be explained by current models of evolutionary rates of genes, such as the 'selection for economy' model (Urrutia, 2003), which states that transcription levels are positively related to gene 
compactness and the 'genome design' model (Vinogradov, 2004), which posits that broadly transcribed genes might require a more complex regulatory mechanism and, thus, have longer introns containing regulatory elements.

From a structural biology perspective, RIOKs can be divided into three subfamilies that all share a conserved, minimal kinase domain, but have different $\mathrm{N}$ - and $\mathrm{C}$-terminal domains. The structural and functional characteristics of the additional ( $\mathrm{N}$ - and $\mathrm{C}$-terminal) domains have not yet been studied in detail; previous studies investigated eubacterial RIOK crystal structures, which lack most of these domains (Campbell et al., 2011). Using the structure of Cth-RIOK-2 (fungus) (Ferreira-Cerca et al., 2012), we generated ab initio structural models for the $C$. elegans RIOKs and, for the first known time, studied some of the $\mathrm{N}$ - and $\mathrm{C}$-terminal regions, which were external to the minimal kinase domain. The 3D structure of this domain is conserved among $C$. elegans RIOKs, as are the secondary structural elements that position the three essential functional kinase loops, namely the P-loop (ATP-binding region), the catalytic-loop (transfer of the phosphate group) and the metal binding loop (binding one or two manganese ions to help catalyse the phosphate transfer). Currently, RIOKs are classified as atypical kinases, because they lack the activation loop which, in other kinases, is located between the catalytic and the metal-binding loops and binds to the substrate (Manning et al., 2002). For this reason, the substrate(s) of RIOKs and the kinase mechanism itself remain unclear. The flexible loop, located in the N-lobe, between the third $\beta$-strand and the subsequent $\alpha$-helix, is characteristic of RIOKs (LaRonde-LeBlanc and Wlodawer, 2005a; Hu et al., 2008), and might substitute the missing activation loop, due to its known involvement in recruiting fungal Cth-RIOK-2 to the pre-40S particle during ribosomal biogenesis (Ferreira-Cerca et al., 2012). Sequence conservation between the flexible loop of Cth-RIOK-2 and the three Cel-RIOKs suggests a similar function of this loop in interacting with the ribosomal complex. The regions external to the minimum kinase domain might also play a role in substrate binding for phosphorylation. Alternatively, RIOKs might not have canonical serine/threonine kinase substrates, but rather have evolved to be ATPases, as suggested by the in vitro ATPase activity of Cth-RIOK-2 (Ferreira-Cerca et al., 2012).

To date, no sequence-based homology could be found between the $\mathrm{N}$ - and C-terminal domains of RIOK-1 or RIOK-3 of nematodes and any other known proteins. Therefore, we built ab initio models for these DUFs against known structural elements, and predicted possible functions independent from the minimum kinase domains based on allocated GO terms. The Cel-RIOK-1-N-DUF is predicted to be involved in actin binding and cellular protein localisation. For Cel-RIOK-1-C-DUF, one of the predicted functional annotations was 'kinase regulator activity'. Deletion of this C-terminal domain (the four C-terminal $\alpha$-helices) from both RIOK-1 and -2 leads to lethal phenotypes in yeast and fungus (Ferreira-Cerca et al., 2012) and, despite being dispensable for kinase activity, these helices have been suggested to be involved in protein-protein interactions; the C-terminal region of RIOK of the tobacco plant is suggested to interact with a viral molecule, inhibiting the cell -to-cell transport of viral RNA (Yoshioka et al., 2004). Additionally, the recently solved crystal structure of Cth-RIOK-2 showed that its $\mathrm{C}$-terminal domain binds between the $\mathrm{N}$ - and $\mathrm{C}$-terminal lobes of the kinase domain and inhibits kinase activity (Ferreira-Cerca et al., 2012). This self-inhibiting feature has been identified in other kinases (Xu et al., 1999; Malakhova et al., 2008; Li et al., 2012). The Cel-RIOK-1 C-terminal domain is structurally similar to the thus, also play a regulatory role by inhibiting kinase activity (Ferreira-Cerca et al., 2012). The Cel-RIOK-3-N-DUF domain is a large domain (242 aa) and is predicted to be involved in transmembrane transport (ATP-regulated), while the short C-terminal domain (Cel-RIOK-3-C-DUF) is suggested to be involved in ion Cth-RIOK-2 C-terminal domain (four- $\alpha$-helix-bundle) and might,

binding. Remarkably, the predicted functional annotation of 'lipid binding' for RIOK-2 and -3 suggests that the RIOK family represents an evolutionary link between prokaryote lipid kinases and eukaryotic kinases. The N-terminal domain of Cel-RIOK-2 has a wingedhelix fold (LaRonde-LeBlanc and Wlodawer, 2005b) that allows interactions with nucleic acids (Aravind et al., 2005), which accords with reports of an involvement of RIOK-2 in ribosomal RNA processing (Vanrobays et al., 2001; Schäfer et al., 2003; LaRonde-LeBlanc and Wlodawer, 2004; Granneman et al., 2010; Ferreira-Cerca et al., 2012; Read et al., 2013).

From a drug targeting perspective, the bulk of current protein kinase inhibitors have been designed to target one family of protein kinases, namely the tyrosine kinases, with more than 150 compounds that are currently in clinical trials for cancer treatments, predicted to generate a global annual revenue exceeding $\$ 30$ billion (Cohen and Alessi, 2013). Other kinase families are only now starting to receive attention due to their involvement in diseases such as hypertension (Wilson et al., 2001), Parkinson's disease (Hardy, 2010) and inflammatory and autoimmune diseases (Clark et al., 2012). Initially, inhibitors were designed to target the ATP-binding pocket directly. However, this approach required very potent compounds to compete with ATP, and did not guarantee kinase specificity. A promising strategy is to target neighbouring hydrophobic pockets that are unique to a specific protein kinase, in particular the back pocket of the ATP-binding site (Cohen and Alessi, 2013). However, the most desirable approach for nematocides is to identify compounds that inhibit the activation of a specific kinase, which render the ATP-binding pocket a less preferred target. An example of such rational design is the inhibition of the Akt kinase activation by a highly specific compound, called Akti1/2. The inactivation of Akt is achieved through targeting a region outside of the kinase domain and preventing the conformational change needed for an upstream kinase (PDK1) to phosphorylate and activate Akt (Barnett et al., 2005; Calleja et al., 2009; Green et al., 2008; Hirai et al., 2010).

In the present study, we were guided by results from previous investigations (Hu et al., 2008; Campbell et al., 2011; Ansell et al., 2013) of RIOKs in strongylid nematodes. We showed that these riok genes are active during the parasitic stages. In addition, elevated transcription of rioks in the ovaries of female vinegar flies (Graveley et al., 2011) indicate a link between these kinases and the reproductive process. A similar function for rioks in the reproductive system of parasitic nematodes might represent an "Achilles heel", enabling drug development. Previous work (Campbell et al., 2011) focused on targeting the minimum kinase domain of Hco-RIOK-1, in particular the ATP-binding pocket. However, our current evidence from the present functional and structural investigation indicates that RIOK-2 might also be a drug target candidate. The crystal structure of the fungal Cth-RIOK-2 allows the study of the back pocket of the ATP-binding region and the design of specific compounds to bind these hydrophobic residues. The functional importance of the $\mathrm{C}$-terminal domains of RIOK-1 and RIOK-2 (with kinase-inhibiting activity) (Angermayr and Bandlow, 2002; Ferreira-Cerca et al., 2012) and their flexible loop (interacting with the ribosomal complex) (Ferreira-Cerca et al., 2012) appear to make these regions ideal for the design of specific compounds that can inhibit RIOK activation or interactions.

\section{Acknowledgements}

This project was funded by the National Health and Medical Q2 651 Research Council (NHMRC) of Australia, and the Australian Q3 652 Research Council (ARC). This project was also supported by a Victorian Life Sciences Computation Initiative (VLSCI), Australia, grant number VR0007 on its Peak Computing Facility at the

\section{3}

654 655 
University of Melbourne, Australia an initiative of the Victorian Government. Other support from the Australian Academy of Science, the Australian-American Fulbright Commission, Alexander von Humboldt Foundation, Germany, Melbourne Water Corporation, Australia (R.B.G.) is gratefully acknowledged, as is funding from the Howard Hughes Medical Institute (HHMI), USA, and National Institutes of Health (NIH), USA (P.W.S.). N.D.Y is an NHMRC Early Career Research Fellow (ECRF). Thanks to Brendan Ansell for discussions and advice on the use of i-TASSER. We also acknowledge the contributions of all staff at WormBase (www.wormbase.org). Data for S. ratti (GenBank assembly ID: GCA_000208845.1) and B. malayi (RNA-seq, PRJEB2709) were kindly provided by the Wellcome Trust Sanger Institute, UK (http://www.ebi.ac.uk/ena/data/view/PRJEB2709). We acknowledge the use of the program I-TASSER - (c) 2013 The Regents of the University of Michigan, USA.

\section{Appendix A. Supplementary data}

Supplementary data associated with this article can be found, in the online version, at http://dx.doi.org/10.1016/j.ijpara.2014.06.005.

\section{References}

Abad, P., Gouzy, J., Aury, J.-M., Castagnone-Sereno, P., Danchin, E.G.J., Deleury, E., Perfus-Barbeoch, L., Anthouard, V., Artiguenave, F., Blok, V.C., Caillaud, M.-C., Coutinho, P.M., Dasilva, C., De Luca, F., Deau, F., Esquibet, M., Flutre, T. Goldstone, J.V., Hamamouch, N., Hewezi, T., Jaillon, O., Jubin, C., Leonetti, P., Magliano, M., Maier, T.R., Markov, G.V., McVeigh, P., Pesole, G., Poulain, J., Robinson-Rechavi, M., Sallet, E., Ségurens, B., Steinbach, D., Tytgat, T., Ugarte, E., van Ghelder, C., Veronico, P., Baum, T.J., Blaxter, M., Bleve-Zacheo, T., Davis, E.L. Ewbank, J.J., Favery, B., Grenier, E., Henrissat, B., Jones, J.T., Laudet, V., Maule, A.G., Quesneville, H., Rosso, M.-N., Schiex, T., Smant, G., Weissenbach, J., Wincker, P., 2008. Genome sequence of the metazoan plant-parasitic nematode Meloidogyne incognita. Nat. Biotechnol. 26, 909-915.

Angermayr, M., Bandlow, W., 2002. RIO1, an extraordinary novel protein kinase. FEBS Lett. 524, 31-36.

Ansell, B.R., Schnyder, M., Deplazes, P., Korhonen, P.K., Young, N.D., Hall, R.S., Mangiola, S., Boag, P.R., Hofmann, A., Sternberg, P.W., Jex, A.R., Gasser, R.B. 2013. Insights into the immuno-molecular biology of Angiostrongylus vasorum through transcriptomics - prospects for new interventions. Biotechnol. Adv. 31, 1486-1500.

Aravind, L., Anantharaman, V., Balaji, S., Babu, M.M., Iyer, L.M., 2005. The many faces of the helix-turn-helix domain: transcription regulation and beyond. FEMS Microbiol. Rev. 29, 231-262.

Ashrafi, K., Chang, F.Y., Watts, J.L., Fraser, A.G., Kamath, R.S., Ahringer, J., Ruvkun, G., 2003. Genome-wide RNAi analysis of Caenorhabditis elegans fat regulatory genes. Nature 421, 268-272.

Balklava, Z., Pant, S., Fares, H., Grant, B.D., 2007. Genome-wide analysis identifies a general requirement for polarity proteins in endocytic traffic. Nat. Cell Biol. 9, 1066-1073.

Barnett, S.F., Defeo-Jones, D., Fu, S., Hancock, P.J., Haskell, K.M., Jones, R.E., Kahana, J.A., Kral, A.M., Leander, K., Lee, L.L., Malinowski, J., McAvoy, E.M., Nahas, D.D., Robinson, R.G., Huber, H.E., 2005. Identification and characterization of pleckstrin-homology-domain-dependent and isoenzyme-specific Akt inhibitors. Biochem. J. 385, 399-408.

Blaxter, M.L., De Ley, P., Garey, J.R., Liu, L.X., Scheldeman, P., Vierstraete, A. Vanfleteren, J.R., Mackey, L.Y., Dorris, M., Frisse, L.M., Vida, J.T., Thomas, W.K. 1998. A molecular evolutionary framework for the phylum Nematoda. Nature 392, 71-75.

Caenorhabditis elegans Sequencing Consortium, 1998. Genome sequence of the nematode C. elegans: a platform for investigating biology. Science 282, 2012 2018.

Calleja, V., Laguerre, M., Parker, P.J., Larijani, B., 2009. Role of a novel PH-kinase domain interface in $\mathrm{PKB} /$ Akt regulation: structural mechanism for allosteric inhibition. PLoS Biol. 7, e17.

Campbell, B.E., Boag, P.R., Hofmann, A., Cantacessi, C., Wang, C.K., Taylor, P., Hu, M., Sindhu, Z.-U.-D., Loukas, A., Sternberg, P.W., Gasser, R.B., 2011. Atypical (RIO) protein kinases from Haemonchus contortus - promise as new targets for nematocidal drugs. Biotechnol. Adv. 29, 338-350.

Ceron, J., Rual, J.-F., Chandra, A., Dupuy, D., Vidal, M., van den Heuvel, S., 2007. Largescale RNAi screens identify novel genes that interact with the $C$. elegans retinoblastoma pathway as well as splicing-related components with synMuv B activity. BMC Dev. Biol. 7, 30

Choi, S.S., Hannenhalli, S., 2013. Three independent determinants of protein evolutionary rate. J. Mol. Evol. 76, 98-111.

Clark, K., MacKenzie, K.F., Petkevicius, K., Kristariyanto, Y., Zhang, J., Choi, H.G., Peggie, M., Plater, L., Pedrioli, P.G.A., McIver, E., Gray, N.S., Arthur, J.S.C., Cohen,
P., 2012. Phosphorylation of CRTC3 by the salt-inducible kinases controls the interconversion of classically activated and regulatory macrophages. Proc. Natl. Acad. Sci. U.S.A. 109, 16986-16991.

Cohen, P., Alessi, D.R., 2013. Kinase drug discovery - what's next in the field? ACS Chem. Biol. 8, 96-104.

Crooks, G.E., Hon, G., Chandonia, J.-M., Brenner, S.E., 2004. WebLogo: a sequence logo generator. Genome Res. 14, 1188-1190

Desjardins, C.A., Cerqueira, G.C., Goldberg, J.M., Hotopp, J.C.D., Haas, B.J., Zucker, J., Ribeiro, J.M.C., Saif, S., Levin, J.Z., Fan, L., Zeng, Q., Russ, C., Wortman, J.R., Fink, D.L., Birren, B.W., Nutman, T.B., 2013. Genomics of Loa loa, a Wolbachia-free filarial parasite of humans. Nature Publishing Group 45, 495-500.

Dieterich, C., Clifton, S.W., Schuster, L.N., Chinwalla, A., Delehaunty, K., Dinkelacker, I., Fulton, L., Fulton, R., Godfrey, J., Minx, P., Mitreva, M., Roeseler, W., Tian, H., Witte, H., Yang, S.-P., Wilson, R.K., Sommer, R.J., 2008. The Pristionchus pacificus genome provides a unique perspective on nematode lifestyle and parasitism. Nat. Genet. 40, 1193-1198.

Edgar, R.C., 2004. MUSCLE: multiple sequence alignment with high accuracy and high throughput. Nucleic Acids Res. 32, 1792-1797.

Esser, D., Siebers, B., 2013. Atypical protein kinases of the RIO family in archaea. Biochem. Soc. Trans. 41, 399-404.

Ferreira-Cerca, S., Sagar, V., Schäfer, T., Diop, M., Wesseling, A.-M., Lu, H., Chai, E., Hurt, E., LaRonde-LeBlanc, N., 2012. ATPase-dependent role of the atypical kinase Rio 2 on the evolving pre-40S ribosomal subunit. Nat. Struct. Mol. Biol. 19, 1316-1323.

Fraser, A.G., Kamath, R.S., Zipperlen, P., Martinez-Campos, M., Sohrmann, M., Ahringer, J., 2000. Functional genomic analysis of C. elegans chromosome I by systematic RNA interference. Nature 408, 325-330.

Geerlings, T.H., Faber, A.W., Bister, M.D., Vos, J.C., Raué, H.A., 2003. Rio2p, an evolutionarily conserved, low abundant protein kinase essential for processing of 20 S Pre-rRNA in Saccharomyces cerevisiae. J. Biol. Chem. 278, 22537-22545.

Geldhof, P., Murray, L., Couthier, A., Gilleard, J.S., McLauchlan, G., Knox, D.P., Britton, C., 2006. Testing the efficacy of RNA interference in Haemonchus contortus. Int. J. Parasitol. 36, 801-810.

Ghedin, E., Wang, S., Spiro, D., Caler, E., Zhao, Q., Crabtree, J., Allen, J.E., Delcher, A.L., Guiliano, D.B., Miranda-Saavedra, D., Angiuoli, S.V., Creasy, T., Amedeo, P., Haas, B., El-Sayed, N.M., Wortman, J.R., Feldblyum, T., Tallon, L., Schatz, M., Shumway, M., Koo, H., Salzberg, S.L., Schobel, S., Pertea, M., Pop, M., White, O., Barton, G.J., Carlow, C.K., Crawford, M.J., Daub, J., Dimmic, M.W., Estes, C.F., Foster, J.M., Ganatra, M., Gregory, W.F., Johnson, N.M., Jin, J., Komuniecki, R., Korf, I., Kumar, S., Laney, S., Li, B.W., Li, W., Lindblom, T.H., Lustigman, S., Ma, D., Maina, C.V., Martin, D.M., McCarter, J.P., McReynolds, L., Mitreva, M., Nutman, T.B., Parkinson, J., Peregrin-Alvarez, J.M., Poole, C., Ren, Q., Saunders, L., Sluder, A.E., Smith, K., Stanke, M., Unnasch, T.R., Ware, J., Wei, A.D., Weil, G., Williams, D.J., Zhang, Y., Williams, S.A., Fraser-Liggett, C., Slatko, B., Blaxter, M.L., Scott, A.L., 2007. Draft genome of the filarial nematode parasite Brugia malayi. Science 317, 1756-1760.

Granneman, S., Petfalski, E., Swiatkowska, A., Tollervey, D., 2010. Cracking pre-40S ribosomal subunit structure by systematic analyses of RNA-protein crosslinking. EMBO J. 29, 2026-2036.

Graveley, B.R., Brooks, A.N., Carlson, J.W., Duff, M.O., Landolin, J.M., Yang, L., Artieri, C.G., van Baren, M.J., Boley, N., Booth, B.W., Brown, J.B., Cherbas, L., Davis, C.A. Dobin, A., Li, R., Lin, W., Malone, J.H., Mattiuzzo, N.R., Miller, D., Sturgill, D., Tuch, B.B., Zaleski, C., Zhang, D., Blanchette, M., Dudoit, S., Eads, B., Green, R.E., Hammonds, A., Jiang, L., Kapranov, P., Langton, L., Perrimon, N., Sandler, J.E., Wan, K.H., Willingham, A., Zhang, Y., Zou, Y., Andrews, J., Bickel, P.J., Brenner, S.E., Brent, M.R., Cherbas, P., Gingeras, T.R., Hoskins, R.A., Kaufman, T.C., Oliver, B., Celniker, S.E., 2011. The developmental transcriptome of Drosophila melanogaster. Nature 471, 473-479.

Green, C.J., Göransson, O., Kular, G.S., Leslie, N.R., Gray, A., Alessi, D.R., Sakamoto, K., Hundal, H.S., 2008. Use of Akt inhibitor and a drug-resistant mutant validates a critical role for protein kinase $\mathrm{B} / \mathrm{Akt}$ in the insulin-dependent regulation of glucose and system A amino acid uptake. J. Biol. Chem. 283, 27653-27667.

Gupta, B.P., Sternberg, P.W., 2003. The draft genome sequence of the nematode Caenorhabditis briggsae, a companion to C. elegans. Genome Biol. 4, 238.

Hanks, S.K., Quinn, A.M., Hunter, T., 1988. The protein kinase family: conserved features and deduced phylogeny of the catalytic domains. Science 241, 42-52. Hardy, J., 2010. Genetic analysis of pathways to Parkinson disease. Neuron 68, 201206.

Hirai, H., Sootome, H., Nakatsuru, Y., Miyama, K., Taguchi, S., Tsujioka, K., Ueno, Y., Hatch, H., Majumder, P.K., Pan, B.-S., Kotani, H., 2010. MK-2206, an allosteric Akt inhibitor, enhances antitumor efficacy by standard chemotherapeutic agents or molecular targeted drugs in vitro and in vivo. Mol. Cancer Ther. 9, 1956-1967.

Hotez, P.J., Fenwick, A., Savioli, L., Molyneux, D.H., 2009. Rescuing the bottom billion through control of neglected tropical diseases. Lancet 373, 1570-1575.

Hu, M., LaRonde-LeBlanc, N., Sternberg, P.W., Gasser, R.B., 2008. Tv-RIO1 - an atypical protein kinase from the parasitic nematode Trichostrongylus vitrinus. Parasite Vectors $1,34$.

Jex, A.R., Liu, S., Li, B., Young, N.D., Hall, R.S., Li, Y., Yang, L., Zeng, N., Xu, X., Xiong, Z., Chen, F., Wu, X., Zhang, G., Fang, X., Kang, Y., Anderson, G.A., Harris, T.W. Campbell, B.E., Vlaminck, J., Wang, T., Cantacessi, C., Schwarz, E.M., Ranganathan, S., Geldhof, P., Nejsum, P., Sternberg, P.W., Yang, H., Wang, J., Gasser, R.B., 2011. Ascaris suum draft genome. Nature 479, 529-533.

Kannan, N., Taylor, S.S., Zhai, Y., Venter, J.C., Manning, G., 2007. Structural and functional diversity of the microbial kinome. PLoS Biol. 5, 467-478.

Keiser, J., Utzinger, J., 2010. The drugs we have and the drugs we need against major helminth infections. Adv. Parasitol. 73, 197-230. 
Kent, W.J., 2002. BLAT - the BLAST-like alignment tool. Genome Res. 12, 656-664. Kikuchi, T., Cotton, J.A., Dalzell, J.J., Hasegawa, K., Kanzaki, N., McVeigh, P., Takanashi, T., Tsai, I.J., Assefa, S.A., Cock, P.J.A., Otto, T.D., Hunt, M., Reid, A.J., Sanchez-Flores, A., Tsuchihara, K., Yokoi, T., Larsson, M.C., Miwa, J., Maule, A.G., Sahashi, N., Jones, J.T., Berriman, M., 2011. Genomic insights into the origin of parasitism in the emerging plant pathogen Bursaphelenchus xylophilus. PLoS Pathog. 7, e1002219.

Krylov, D.M., Wolf, Y.I., Rogozin, I.B., Koonin, E.V., 2003. Gene loss, protein sequence divergence, gene dispensability, expression level, and interactivity are correlated in eukaryotic evolution. Genome Res. 13, 2229-2235.

Laing, R., Kikuchi, T., Martinelli, A., Tsai, I.J., Beech, R.N., Redman, E., Holroyd, N., Bartley, D.J., Beasley, H., Britton, C., Curran, D., Devaney, E., Gilabert, A., Hunt, M., Jackson, F., Johnston, S.L., Kryukov, I., Li, K., Morrison, A.A., Reid, A.J., Sargison, N., Saunders, G.I., Wasmuth, J.D., Wolstenholme, A., Berriman, M., Gilleard, J.S., Cotton, J.A., 2013. The genome and transcriptome of Haemonchus contortus, a key model parasite for drug and vaccine discovery. Genome Biol. 14, R88.

LaRonde-LeBlanc, N., Wlodawer, A., 2004. Crystal structure of A. fulgidus Rio2 defines a new family of serine protein kinases. Structure 12, 1585-1594.

LaRonde-LeBlanc, N., Wlodawer, A., 2005a. A family portrait of the RIO kinases. J. Biol. Chem. 280, 37297-37300.

LaRonde-LeBlanc, N., Wlodawer, A., 2005b. The RIO kinases: an atypical protein kinase family required for ribosome biogenesis and cell cycle progression. Biochim. Biophys. Acta 1754, 14-24.

LaRonde-LeBlanc, N., Guszczynski, T., Copeland, T., Wlodawer, A., 2005. Structure and activity of the atypical serine kinase Rio1. FEBS J. 272, 3698-3713.

Larracuente, A.M., Sackton, T.B., Greenberg, A.J., Wong, A., Singh, N.D., Sturgill, D. Zhang, Y., Oliver, B., Clark, A.G., 2008. Evolution of protein-coding genes in Drosophila. Trends Genet. 24, 114-123.

Li, H., Durbin, R., 2010. Fast and accurate long-read alignment with BurrowsWheeler transform. Bioinformatics 26, 589-595.

Li, H., Handsaker, B., Wysoker, A., Fennell, T., Ruan, J., Homer, N., Marth, G., Abecasis, G., Durbin, R.1000 Genome Project Data Processing Subgroup, 2009. The sequence alignment/map format and SAMtools. Bioinformatics 25, 2078-2079.

Li, D., Fu, T.M., Nan, J., Liu, C., Li, L.F., Su, X.D., 2012. Structural basis for the autoinhibition of the C-terminal kinase domain of human RSK1. Acta Crystallogr. D Biol. Crystallogr. 68, 680-685.

Liao, B.-Y., Zhang, J., 2006. Low rates of expression profile divergence in highly expressed genes and tissue-specific genes during mammalian evolution. Mol. Biol. Evol. 23, 1119-1128.

Malakhova, M. Tereshko, V., Lee, S.-Y., Yao, K., Cho, Y.-Y., Bode, A., Dong, Z., 2008. Structural basis for activation of the autoinhibitory C-terminal kinase domain of p90 RSK2. Nat. Struct. Mol. Biol. 15, 112-113.

Manning, G., Whyte, D.B., Martinez, R., Hunter, T., Sudarsanam, S., 2002. The protein kinase complement of the human genome. Science 298, 1912-1934.

Manning, G., Reiner, S.D., Lauwaet, T., Dacre, M., Smith, A., Zhai, Y., Svard, S., Gillin, D.F., 2011. The minimal kinome of Giardia lamblia illuminates early kinase evolution and unique parasite biology. Genome Biol. 12, R66.

Maule, A.G., McVeigh, P., Dalzell, J.J., Atkinson, L., Mousley, A., Marks, N.J., 2011. An eye on RNAi in nematode parasites. Trends Parasitol 27, 505-513.

Mitreva, M., Jasmer, D.P., Zarlenga, D.S., Wang, Z., Abubucker, S., Martin, J., Taylor, C.M., Yin, Y., Fulton, L., Minx, P., Yang, S.-P., Warren, W.C., Fulton, R.S., Bhonagiri, V., Zhang, X., Hallsworth-Pepin, K., Clifton, S.W., McCarter, J.P., Appleton, J., Mardis, E.R., Wilson, R.K., 2011. The draft genome of the parasitic nematode Trichinella spiralis. Nat. Genet. 43, 228-235.

Opperman, C.H., Bird, D.M., Williamson, V.M., Rokhsar, D.S., Burke, M., Cohn, J., Cromer, J., Diener, S., Gajan, J., Graham, S., Houfek, T.D., Liu, Q., Mitros, T., Schaff, J., Schaffer, R., Scholl, E., Sosinski, B.R., Thomas, V.P., Windham, E., 2008. Sequence and genetic map of Meloidogyne hapla: a compact nematode genome for plant parasitism. Proc. Natl. Acad. Sci. U.S.A. 105, 14802-14807.

Osei-Atweneboana, M.Y., Awadzi, K., Attah, S.K., Boakye, D.A., Gyapong, J.O., Prichard, R.K., 2011. Phenotypic evidence of emerging ivermectin resistance in Onchocerca volvulus. PLoS Negl. Trop. Dis. 5, e998.

Read, R.D., Fenton, T.R., Gomez, G.G., Wykosky, J., Vandenberg, S.R., Babic, I., Iwanami, A., Yang, H., Cavenee, W.K., Mischel, P.S., Furnari, F.B., Thomas, J.B., 2013. A kinome-wide RNAi screen in Drosophila glia reveals that the RIO kinases mediate cell proliferation and survival through TORC2-Akt signaling in glioblastoma. PLoS Genet. 9, e1003253.
Robinson, M.D., McCarthy, D.J., Smyth, G.K., 2010. EdgeR: a bioconductor package for differential expression analysis of digital gene expression data. Bioinformatics 26, 139-140.

Roy, A., Kucukural, A., Zhang, Y., 2010. I-TASSER: a unified platform for automated protein structure and function prediction. Nat. Protoc. 5, 725-738.

Roy, A., Yang, J., Zhang, Y., 2012. COFACTOR: an accurate comparative algorithm for structure-based protein function annotation. Nucleic Acids Res. 40, W471W477.

Rual, J.-F., Ceron, J., Koreth, J., Hao, T., Nicot, A.-S., Hirozane-Kishikawa, T., Vandenhaute, J., Orkin, S.H., Hill, D.E., van den Heuvel, S., Vidal, M., 2004. Toward improving Caenorhabditis elegans phenome mapping with an ORFeomebased RNAi library. Genome Res. 14, 2162-2168.

Schäfer, T., Strauss, D., Petfalski, E., Tollervey, D., Hurt, E., 2003. The path from nucleolar 90S to cytoplasmic 40S pre-ribosomes. EMBO J. 22, 1370-1380.

Schwarz, E.M., Korhonen, P.K., Campbell, B.E., Young, N.D., Jex, A.R., Jabbar, A., Hall, R.S., Mondal, A., Howe, A.C., Pell, J., Hofmann, A., Boag, P.R., Zhu, X.-Q., Gregory, T.R., Loukas, A., Williams, B.A., Antoshechkin, I., Brown, C.T., Sternberg, P.W., Gasser, R.B., 2013. The genome and developmental transcriptome of the strongylid nematode Haemonchus contortus. Genome Biol. 14, R89.

Simpson, K.J., Selfors, L.M., Bui, J., Reynolds, A., Leake, D., Khvorova, A., Brugge, J.S., 2008. Identification of genes that regulate epithelial cell migration using an siRNA screening approach. Nat. Cell Biol. 10, 1027-1038.

Slater, G.S.C., Birney, E., 2005. Automated generation of heuristics for biological sequence comparison. BMC Bioinformatics 6, 31.

Sönnichsen, B., Koski, L.B., Walsh, A., Marschall, P., Neumann, B., Brehm, M., Alleaume, A.-M., Artelt, J., Bettencourt, P., Cassin, E., Hewitson, M., Holz, C Khan, M., Lazik, S., Martin, C., Nitzsche, B., Ruer, M., Stamford, J., Winzi, M., Heinkel, R., Röder, M., Finell, J., Häntsch, H., Jones, S.J.M., Jones, M., Piano, F., Gunsalus, K.C., Oegema, K., Gönczy, P., Coulson, A., Hyman, A.A., Echeverri, C.J., 2005. Full-genome RNAi profiling of early embryogenesis in Caenorhabditis elegans. Nature 434, 462-469.

Srinivasan, J., Dillman, A.R., Macchietto, M.G., Heikkinen, L., Lakso, M., Fracchia, K.M., Antoshechkin, I., Mortazavi, A., Wong, G., Sternberg, P.W., 2013. The draf genome and transcriptome of Panagrellus redivivus are shaped by the harsh demands of a free-living lifestyle. Genetics 193, 1279-1295.

Strunk, B.S., Loucks, C.R., Su, M., Vashisth, H., Cheng, S., Schilling, J., Brooks, C.L., Karbstein, K., Skiniotis, G., 2011. Ribosome assembly factors prevent premature translation initiation by $40 \mathrm{~S}$ assembly intermediates. Science 333, 1449-1453.

Urrutia, A.O., 2003. The signature of selection mediated by expression on human genes. Genome Res. 13, 2260-2264.

Vanrobays, E., Gleizes, P.E., Bousquet-Antonelli, C., Noaillac-Depeyre, J., CaizerguesFerrer, M., Gélugne, J.P., 2001. Processing of 20S pre-rRNA to 18 S ribosomal RNA in yeast requires Rrp10p, an essential non-ribosomal cytoplasmic protein. EMBO J. 20, 4204-4213.

Vinogradov, A.E., 2004. Compactness of human housekeeping genes: selection for economy or genomic design? Trends Genet. 20, 248-253.

Wang, Z., Zhang, J., 2009. Why is the correlation between gene importance and gene evolutionary rate so weak? PLoS Genet. 5, e1000329.

Wang, C.K., Broder, U., Weeratunga, S.K., Gasser, R.B., Loukas, A., Hofmann, A., 2012. SBAL: a practical tool to generate and edit structure-based amino acid sequence alignments. Bioinformatics 28, 1026-1027.

Widmann, B., Wandrey, F., Badertscher, L., Wyler, E., Pfannstiel, J., Zemp, I., Kutay, U., 2012. The kinase activity of human Rio1 is required for final steps of cytoplasmic maturation of 40S subunits. Mol. Biol. Cell 23, 22-35.

Wilson, F.H., Disse-Nicodème, S., Choate, K.A., Ishikawa, K., Nelson-Williams, C., Desitter, I., Gunel, M., Milford, D.V., Lipkin, G.W., Achard, J.M., Feely, M.P., Dussol, B., Berland, Y., Unwin, R.J., Mayan, H., Simon, D.B., Farfel, Z., Jeunemaitre, X., Lifton, R.P., 2001. Human hypertension caused by mutations in WNK kinases. Science 293, 1107-1112.

Xu, W., Doshi, A., Lei, M., Eck, M.J., Harrison, S.C., 1999. Crystal structures of c-Src reveal features of its autoinhibitory mechanism. Mol. Cell 3, 629-638.

Yoshioka, K., Matsushita, Y., Kasahara, M., Konagaya, K.-I., Nyunoya, H., 2004. Interaction of tomato mosaic virus movement protein with tobacco RIO kinase. Mol. Cells 17, 223-229.

Zhang, Y., 2008. I-TASSER server for protein 3D structure prediction. BMC Bioinformatics 9,40 . 